\title{
A fuzzy MCDM framework for the environmental pollution potential of industries focusing on air pollution
}

\author{
R. K. $\operatorname{Lad}^{1}$, R. A. Christian ${ }^{1}$ \& A. W. Deshpande ${ }^{2}$ \\ ${ }^{1}$ Department of Civil Engineering, \\ Sardar Vallabhabhai National Institute of Technology, Surat, India \\ ${ }^{2}$ Chair: Berkeley Initiative in Soft Computing (BISC), \\ Special Interest Group (SIG), \\ Environment Management Systems (EMS), \\ Guest Faculty: University of California, Berkeley, California, USA
}

\begin{abstract}
The industrial policies of developing countries mainly focusing on the pursuit of economic growth with inadequate importance given to environmental pollution issues has resulted in rapid degradation of the natural environment. As the ambience has a dilution limit, industries that have been emitting air pollutants within the permissible pollution norms also contribute their share towards overall environmental degradation. Expressing permissible limits of pollution parameters on the dichotomous scale (Yes/No) needs a paradigm shift from crisp (Permissible OR Not Permissible) to fuzzy values (Permissible AND Not Permissible). A fresh look at the pollution control strategies is, therefore, necessary. An attempt has been made to address this problem and a new formalism of integrated effects of air pollutants is proposed for industries based on their air emissions. Vagueness in the perception of environmental experts for evaluating the techno-scientific parameters in linguistic terms for specific usage, coupled with imprecision in parametric data calls for the application of fuzzy modelling. In this study, importance is given to each air pollutant and a composite index is developed, which can reflect the air pollution potential of an industry. The study also reflects a case study of stringent environmental standards reflecting the rise in the pollution potential of industries. This can be linked to policy framing based on the principle of the polluter paying to control the pollution levels in the environment. The case study relates to the application of Fuzzy Multi Criteria Decision Making (FMCDM) for ranking the industries located in the State of Gujarat, India. The feasibility of the approach for ranking industries based on their air pollution potential is also discussed.

Keywords: Fuzzy Multi Criteria Decision Making, industrialization, linguistic variables, environmental issues, air pollution potential, fuzzy modelling, environmental experts' perception, stringent emission standards, fuzzy sets, ranking of industries.
\end{abstract}




\section{Introduction}

The rapid industrialization of India in the recent past has been the striking feature of the Indian economic development. The common indicators of economic welfare, such as national product and income have reflected the growth of the industry as a major indicator for the development of the nation. However, the other angle of industrialization has been the serious damage to the surrounding environment due to the wastes and pollutants generated from industries. The regulatory agencies set the norms to control the pollution, but as the ambience has a dilution limit, industries that have been emitting air pollutants within the permissible pollution norms also contribute their share towards overall environmental degradation. The situation is not very different from the case of the parameters relating to water, land and noise pollution. In this context, there is a need to see the pollution potential of industry on the basis of the permissible limit of pollutants. This study can be linked to the principle of "Polluter to Pay" on the basis of degree of certainty of pollution potential to reduce the pollution. This type of problem can be solved by using fuzzy logic. According to Hipel et al. [1], a decision problem is said to be complex and difficult, if there exist multiple criteria - both qualitative and quantitative in nature. Here a methodology is developed, employing the Fuzzy Multiple Criteria Decision Making (FMCDM) approach, for ranking of industries based on their air pollution potential. In this study separate weightage is given to the dust and gaseous criteria of air pollution. The ranking of industry can be done by jointly considering the water and air pollution potential indices [2].

\section{Fuzzy Multi Criteria Decision Making (FMCDM) modelling}

Many attempts have been made to study different methods of ranking alternatives and decision making for problems under fuzzy environment during the last few decades. For the evaluation of the modern concept of uncertainty readers can refer to the publication of a seminal paper by Lotfi A. Zadeh on fuzzy sets [3]. In his paper, Zadeh introduced a theory of objects - fuzzy sets with boundaries that are not precise [4]. Bellman and Zadeh [5] used a concept of fuzzy goals and fuzzy constraints for fuzzy decision. Jain $[6,7]$ proposed a method of using the concept of membership level, whereas Baldwin and Guild [8] indicated that the above two methods suffer from some difficulties for comparing the alternatives and have disadvantages. Adamo introduced the $\alpha$ preference rule using the concept of the $\alpha$-level set. Chang indicated that the method proposed by Adamo [9] may lead to an inappropriate choice and went on to introduce the preference function concept of an alternative. A complete review of fuzzy numbers ranking methods was presented by Bortolan and Degani [10]. Hagemeister et al. [11] developed a methodology for hazard ranking of landfills using fuzzy composite programming, and presented a methodology to assess the environmental and public health hazard posed by an unregulated landfill when available data is imprecise, uncertain or subjective. Raj and Kumar [12] proposed the concept of a maximizing set and a minimizing 
set for ranking alternatives with fuzzy weights. Shen et al. [13] considered the characteristics of the construction business environment in China and identified the key parameters used in assessing contractors' competitiveness for awarding construction contracts in the market on a multi criteria basis. Seo et al. [14] developed a methodology with the help of a fuzzy decision making tool for the assessment of residential buildings, based on the acceptable level of environmental impact and socio-economic characteristics of the residential building. A more recent study by Singh and Tiong [15] highlights a fuzzy framework for contractor selection; this paper presents a systematic procedure based on fuzzy set theory to evaluate the capability of a contractor to deliver the project as per the owner's requirement. The approach developed for the ranking of industries based on their environmental pollution potential is somewhat analogous to the procedure suggested by Singh and Tiong [15]. The methodology discussed here has been successfully used for ranking of the same type of industries [2] considering the seven linguistic variables of Saaty [16].

\subsection{Methodology}

Figure 1 portrays an overview of the fuzzy decision framework to rank industries, which is self-explanatory. Identification of environmental experts is of prime importance. The importance weight for each of the criteria mentioned in Table 2 is developed by consulting environmental experts. To describe the level of performance on decision criteria Saaty [16] has proposed

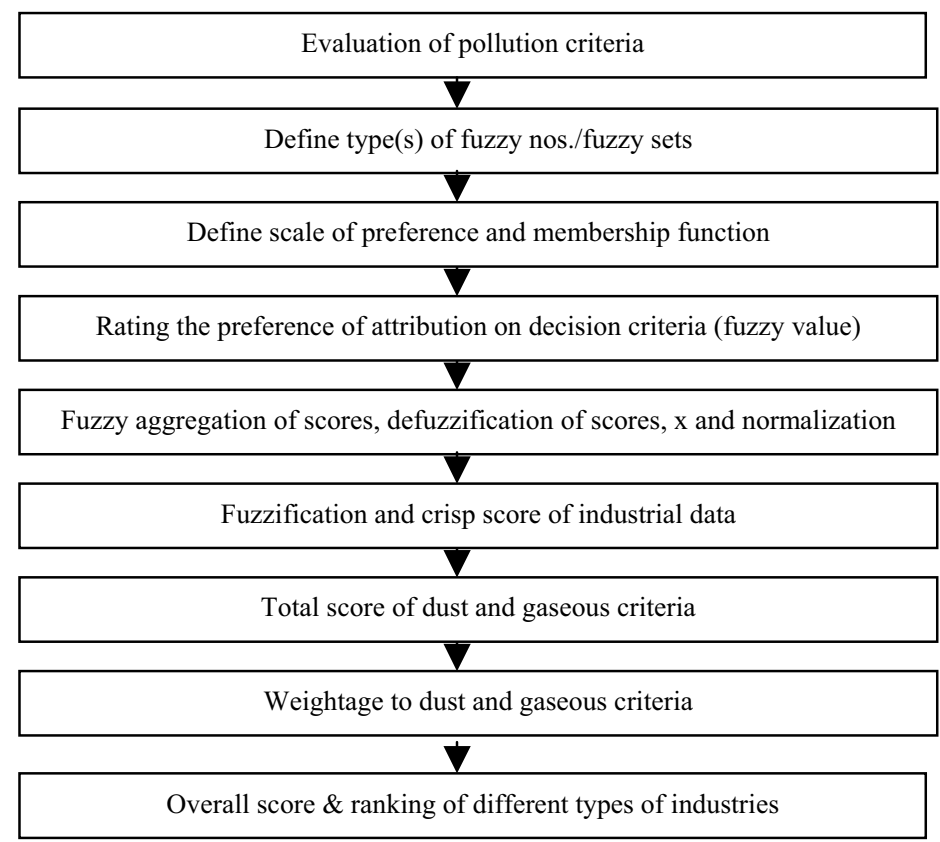

Figure 1: $\quad$ Fuzzy decision framework for industrial ranking. 
fuzzy numbers for seven linguistic variables. In this study, four fuzzy numbers are selected to describe the level of performance on decision criteria in the evaluation of pollution potential of industries. Four linguistic variables are used because it is convenient for an expert to distinguish subjectively between four alternatives. Table 1 shows the linguistic variables and fuzzy numbers used in this study. Figure 2 shows the graphical presentation of fuzzy numbers for the linguistics variables. The importance weight factors are computed for the sub criteria (parameters) of dust (SPM) and gases ( $\mathrm{SOx}, \mathrm{NOx}, \mathrm{Cl}_{2}$ and $\mathrm{HCl}$ ). Table 2 shows experts' opinion for the sub criteria of air pollution.

Table 1: $\quad$ Linguistics variables and fuzzy numbers.

\begin{tabular}{|l|c|}
\hline \multicolumn{1}{|c|}{ Linguistics Variables } & Fuzzy Numbers \\
\hline VI (Very Important) & $(0.72,0.86,1.00,1.00)$ \\
\hline I (Important) & $(0.43,0.57,0.72,0.86)$ \\
\hline A (Average) & $(0.14,0.29,0.43,0.57)$ \\
\hline NI (Not Important) & $(0.00,0.00,0.14,0.29)$ \\
\hline
\end{tabular}

Table 2: $\quad$ Experts' opinion.

\begin{tabular}{|l|c|c|c|c|c|}
\hline Sub Criteria & EE*1 & EE2 & EE3 & EE4 & EE5 \\
\hline Dust \\
\hline SPM, $\mathrm{mg} / \mathrm{Nm}^{3}$ & I & I & VI & VI & VI \\
\hline Gaseous & VI & VI & VI & VI & VI \\
\hline $\mathrm{SO}_{2}, \mathrm{ppm}$ & I & VI & VI & A & VI \\
\hline $\mathrm{NOx}, \mathrm{ppm}$ & NI & A & I & A & NI \\
\hline $\mathrm{Cl}_{2}, \mathrm{mg} / \mathrm{Nm}^{3}$ & NI & NI & A & A & A \\
\hline $\mathrm{HCl}, \mathrm{mg} / \mathrm{Nm}^{3}$ & & &
\end{tabular}

EE*-Environmental Expert

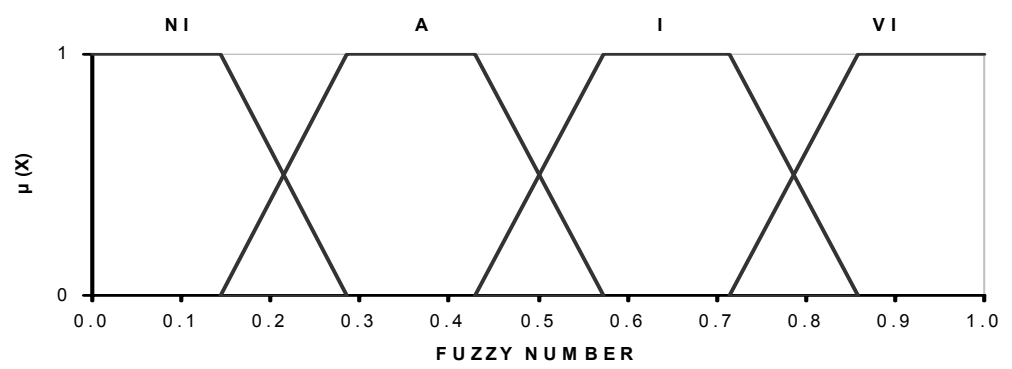

Figure 2: $\quad$ Graphical presentation of fuzzy numbers for linguistic variables.

Using eqn (1) given below, the average fuzzy number for all environmental experts' opinion can be expressed as

$$
A_{i j}^{k}=(1 / \mathrm{p}) \otimes\left(\mathrm{a}_{\mathrm{i} 1}^{\mathrm{k}} \oplus \mathrm{a}_{\mathrm{i} 2}^{\mathrm{k}} \oplus \ldots \oplus \mathrm{a}_{\mathrm{ip}}^{\mathrm{k}}\right) \text { for } \mathrm{j}=1,2, . ., \mathrm{p}
$$


where $a_{i j}^{k}$ is a fuzzy number (weight) assigned to a parameter by environmental experts for the decision criterion $\mathrm{C}_{\mathrm{k}}$ and $\mathrm{p}$ is the number of experts involved in the evaluation process. Using eqn (1) the matrix given above can be further simplified to calculate the average fuzzy number. The linguistic variables as assigned by the experts are converted to fuzzy numbers used in the above expression through Table 1 and Figure 2. Now, the defuzzified values for the sub criteria are obtained by using eqn (2).

$$
\mathrm{E}=\left(\mathrm{x}_{1}+\mathrm{x}_{2}+\mathrm{x}_{3}+\mathrm{x}_{4}\right) / 4
$$

For details about different types of fuzzy numbers, membership functions, aggregation and defuzzification methods, interested readers may refer to Zimmerman [17], Klir and Folger [18] and Kaufmann and Gupta [19].

The normalized weight for each sub criterion of dust and gases is obtained by dividing the scores of each sub criterion $\left(C_{i j}\right)$ of dust and gases by the total of all sub criterions $\left(\sum C_{i j}\right)$ of dust and gases respectively. The next step is to convert the parametric values of stack emissions to the fuzzy numbers (membership functions) based on the specified statutory norms.

Figure 3 shows the fuzzy set for not acceptable (membership function one) for gaseous parameter $\mathrm{HCl}$. Similarly, fuzzy sets for other parameters of dust and gases can be developed.

The fuzzy decision matrix for sub criterion $\mathrm{C}_{15}(\mathrm{HCl})$ can be written as

$$
X_{C_{15}}=\left[\begin{array}{c}
\mu_{1} \mu_{2} \mu_{3} \ldots \mu_{n} \\
\left(a_{1}, a_{2}, a_{3}, \ldots a_{n}\right) \\
\left(b_{1}, b_{2}, b_{3}, \ldots b_{n}\right) \\
\left(c_{1}, c_{2}, c_{3}, \ldots c_{n}\right)
\end{array}\right]\left|\begin{array}{l}
\mid \\
l_{1} \\
l_{2} \\
I_{n}
\end{array}\right|
$$

where $a_{1}, a_{2}, a_{3} \ldots a_{n}, b_{1}, b_{2}, b_{3} \ldots . . b_{n}$ and $c_{1}, c_{2}, c_{3} \ldots . . c_{n}$ are fuzzy values of $\mathrm{HCl}$ obtained from seasonal monitoring for Industry 1, Industry 2 and Industry $n$ respectively.

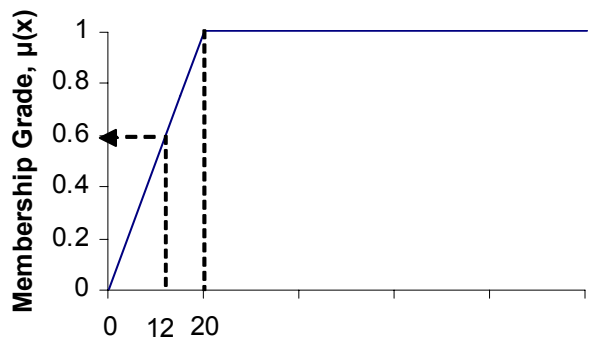

$\mathrm{HCl}(\mathrm{mg} / \mathrm{Nm} 3)$

Figure 3: $\quad$ Pollution parameter $\mathrm{HCl}$ : fuzzy set for not acceptable. 
The crisp scores on the sub criterion $\mathrm{C}_{15}$ for each industry can be obtained using following equations.

Industry $1=\left(a_{1}+a_{2}+a_{3} . . a_{n}\right) / n$,

Industry $2=\left(b_{1}+b_{2}+b_{3} . . b_{n}\right) / n$ and

Industry $\mathrm{n}=\left(c_{1}+c_{2}+c_{3} . . c_{n}\right) / n$

Similarly, crisp scores can be computed for the other sub criteria of dust and gases. Using the simple additive weighing method (Hwang and Yoon [20]), the total scores (TS) for each industry for dust and gaseous criteria can be calculated by eqn (3).

$$
T S=\sum\left(\mathrm{X}_{\mathrm{k}} \otimes \mathrm{W}\left(\mathrm{C}_{\mathrm{k}}\right)\right) \text { for } k=1,2,3 \ldots n
$$

where, $W\left(C_{k}\right)$ = weight or the importance value of the sub criterion $\mathrm{k}$ and

$X_{k} \quad=$ crisp score of the industry data against the sub criterion $\mathrm{k}$.

Using pollution potential importance weight for both the criteria (dust and gaseous) such that their summation is equal to 1 , an overall score (OS) for the industries can be calculated by eqn (4).

$$
\mathrm{O} S=\sum\left(T S_{k i} \otimes W\left(C_{k i}\right)\right) \text { for } k=1,2,3 \ldots n \text { and } i=1,2,3 \ldots . n
$$

where $T S_{k i} \quad=$ total score of the industry i against the criterion $\mathrm{k}$

$$
\begin{gathered}
W\left(C_{k i}\right)=\text { weight or the importance value of the criterion } \mathrm{k} \text { for } \\
\text { industry } \mathrm{i}=T S_{k i} / \sum T S_{k i}
\end{gathered}
$$

\section{Case study}

The case study relates to the available air emission characteristics from three chemical industries, three thermal power station units and three dying and printing textile industries located in Gujarat State, India. Table 3 shows the stack emissions for the above mentioned industries monitored for winter $\left(\mathrm{M}_{1}\right)$, summer $\left(\mathrm{M}_{2}\right)$ and the rainy season $\left(\mathrm{M}_{3}\right)$.

The parametric values of stack emissions are converted to the fuzzy numbers (membership functions) based on the specified statutory norms (see figure 3). For example, for $12 \mathrm{mg} / \mathrm{Nm}^{3}$, the $\mathrm{HCl}$ normalized value is 0.6 . Similarly, normalized values of stack emissions for all industries have been worked out. For the final total score, a unique membership value for each industry for different sub criteria can be obtained by using the simple average. Then the normalized weight for each sub criterion of dust and gases for different industries are calculated.

Using the simple additive weighing method (Hwang and Yoon [20]), the total score (TS) for each industry has been calculated and the same is as shown in Table 4. The matrix (Figure 4) is shown for the total score of the sub criteria of gases for chemical industries. 
Table 3: $\quad$ Effluent characteristics of stack emissions.

\begin{tabular}{|c|c|c|c|c|c|c|c|c|c|c|}
\hline \multirow{2}{*}{$\begin{array}{l}\text { Sub } \\
\text { Criteria }\end{array}$} & \multirow{2}{*}{$\begin{array}{c}\text { GPCB }^{\#} \\
\text { limit }\end{array}$} & \multicolumn{3}{|c|}{ Industry 1} & \multicolumn{3}{|c|}{ Industry 2} & \multicolumn{3}{|c|}{ Industry 3} \\
\hline & & $\mathrm{M}_{1}$ & $\mathrm{M}_{2}$ & $\mathrm{M}_{3}$ & $\mathrm{M}_{1}$ & $\mathrm{M}_{2}$ & $\mathrm{M}_{3}$ & $\mathrm{M}_{1}$ & $\mathrm{M}_{2}$ & $\mathrm{M}_{3}$ \\
\hline \multicolumn{11}{|c|}{ Chemical Industries } \\
\hline \multicolumn{11}{|c|}{ Air Pollution } \\
\hline \multicolumn{11}{|c|}{ Dust } \\
\hline $\begin{array}{l}\text { SPM, } \\
\mathrm{mg} / \mathrm{Nm}^{3}\end{array}$ & 150 & 60.0 & 55.0 & 80.0 & 20.0 & 175 & 60.0 & 175 & 220 & 159 \\
\hline \multicolumn{11}{|l|}{ Gaseous } \\
\hline $\begin{array}{l}\mathrm{SO}_{\mathrm{X}} \\
\mathrm{ppm}\end{array}$ & 100 & 12.25 & 13.12 & 3.4 & 61.9 & 80.0 & 110 & 15.0 & 25.0 & 45.0 \\
\hline $\begin{array}{l}\mathrm{NO}_{X}, \\
\mathrm{ppm}\end{array}$ & 50 & 21.5 & 30.0 & 36.0 & 58.0 & 49.0 & 55.0 & 14.0 & 35.0 & 36.0 \\
\hline $\begin{array}{l}\mathrm{Cl}_{2}, \\
\mathrm{mg} / \mathrm{Nm}^{3}\end{array}$ & 9 & 4.5 & 3.66 & 3.91 & 0.00 & 0.00 & 0.00 & 0.00 & 0.00 & 0.00 \\
\hline $\begin{array}{l}\mathrm{HCl}, \\
\mathrm{mg} / \mathrm{Nm}^{3}\end{array}$ & 20 & 0.00 & 0.00 & 0.00 & 0.00 & 0.00 & 0.00 & 0.00 & 0.00 & 0.00 \\
\hline \multicolumn{11}{|c|}{ Thermal Power Station Units } \\
\hline \multicolumn{11}{|c|}{ Air Pollution } \\
\hline \multicolumn{11}{|c|}{ Dust } \\
\hline $\begin{array}{l}\text { SPM, } \\
\mathrm{mg} / \mathrm{Nm}^{3}\end{array}$ & 150 & 0.00 & 7.00 & 3.8 & 3.6 & 3.1 & 2.4 & 0.00 & 0.00 & 0.00 \\
\hline \multicolumn{11}{|l|}{ Gaseous } \\
\hline $\begin{array}{l}\mathrm{SO}_{\mathrm{X}} \\
\mathrm{ppm}\end{array}$ & 100 & 3.61 & 6.22 & 12.25 & 12.23 & 9.21 & 6.1 & 4.80 & 4.20 & 6.1 \\
\hline $\begin{array}{l}\mathrm{NO}_{\mathrm{X}} \\
\mathrm{ppm}\end{array}$ & 50 & 7.21 & 6.40 & 10.4 & 140 & 140 & 132 & 7.90 & 7.40 & 7.20 \\
\hline \multicolumn{11}{|c|}{ Dying and Printing Units } \\
\hline \multicolumn{11}{|c|}{ Air Pollution } \\
\hline \multicolumn{11}{|c|}{ Dust } \\
\hline $\begin{array}{l}\text { SPM, } \\
\mathrm{mg} / \mathrm{Nm}^{3}\end{array}$ & 150 & 149 & 128.3 & 132.1 & 117.3 & 96.1 & 101.7 & 148.5 & 134.06 & 135.9 \\
\hline \multicolumn{11}{|l|}{ Gaseous } \\
\hline $\begin{array}{l}\mathrm{SO}_{\mathrm{X}} \\
\mathrm{ppm}\end{array}$ & 100 & 51.48 & 40.80 & 41.5 & 55.05 & 42.82 & 43.62 & 58.21 & 52.74 & 55.25 \\
\hline $\begin{array}{l}\mathrm{NO}_{\mathrm{X}}, \\
\mathrm{ppm}\end{array}$ & 50 & 6.27 & 6.50 & 6.60 & 2.82 & 2.14 & 2.41 & 6.05 & 6.08 & 6.11 \\
\hline
\end{tabular}

\# Gujarat Pollution Control Board

$\left[\begin{array}{l}\text { Sub Criteria } \\ \mathrm{SO} 2 \\ \mathrm{NOx} \\ \mathrm{Cl} 2 \\ \mathrm{HCl}\end{array}\right]\left[\begin{array}{ccc}\mathrm{I} 1 & \mathrm{I} 2 & \mathrm{I} 3 \\ 0.10 & 0.81 & 0.28 \\ 0.58 & 0.99 & 0.57 \\ 0.45 & 0.00 & 0.00 \\ 0.00 & 0.00 & 0.00\end{array}\right]\left[\begin{array}{l}\mathrm{W}_{\mathrm{Ck}} \\ 0.41 \\ 0.33 \\ 0.14 \\ 0.12\end{array}\right]$

Figure 4: Matrix for total score for sub criteria of gaseous of chemical industries. 
Table 4: $\quad$ Total score and summation for criteria of chemical industries.

\begin{tabular}{|c|c|c|c|}
\hline Criteria & I1 & I2 & I3 \\
\hline Dust $\left(\mathrm{C}_{1}\right)$ & 0.433 & 0.511 & 1.000 \\
\hline Gaseous $\left(\mathrm{C}_{2}\right)$ & 0.298 & 0.660 & 0.305 \\
\hline$\sum$ & 0.731 & 1.171 & 1.305 \\
\hline
\end{tabular}

$\left[\begin{array}{l}\text { Criteria } \\ \mathrm{C} 1 \\ \mathrm{C} 2\end{array}\right]\left[\begin{array}{rrc}\mathrm{I} 1 & \mathrm{I} 2 & \mathrm{I} 3 \\ 0.433 & 0.511 & 1.000 \\ 0.298 & 0.660 & 0.305\end{array}\right]\left[\begin{array}{ccc}\mathrm{W}_{\mathrm{Ck} 1} & \mathrm{~W}_{\mathrm{Ck} 2} & \mathrm{~W}_{\mathrm{Ck} 3} \\ 0.593 & 0.437 & 0.767 \\ 0.407 & 0.563 & 0.233\end{array}\right]$

Figure 5: $\quad$ Matrix for overall score for dust and gaseous.

Table 5: $\quad$ Overall score and ranking for different types of industries.

\begin{tabular}{|c|c|c|c|c|c|c|c|c|}
\hline \multicolumn{2}{|c|}{ Chemical Industries } & \multicolumn{3}{c|}{ Thermal Power Station Units } & \multicolumn{3}{|c|}{ Dying and Printing Units } \\
\hline 0.378 & 0.595 & 0.838 & 0.097 & 0.483 & 0.095 & 0.758 & 0.580 & 0.771 \\
\hline 7 & 4 & $\mathbf{1}$ & 8 & 6 & $\mathbf{9}$ & 3 & 5 & 2 \\
\hline
\end{tabular}

Table 6: Overall score and ranking of chemical industries (sensitivity analysis).

\begin{tabular}{|c|c|c|c|c|}
\hline GPCB limit & Criteria & I1 & I2 & I3 \\
\hline $20 \mathrm{ppm}$ & $\mathrm{SO}_{2}$ & 0.444 & 0.645 & 0.849 \\
\hline $100 \mathrm{ppm}$ & $\mathrm{SO}_{2}$ & 0.378 & 0.595 & 0.838 \\
\hline
\end{tabular}

Using pollution potential importance weight for both the criteria (such that their summation is equal to 1) has been calculated. The matrix (Figure 5) is shown for an overall score of dust and gaseous criteria. From that an overall score (OS) for chemical industries has been calculated. Similarly, overall scores for thermal power station units and dying and printing units are calculated and the same are shown in Table 5.

\subsection{Sensitivity analysis}

In order to check the sensitivity of the model for the given sub criteria, it was proposed to operate the model with $\mathrm{SO}_{2}$ emission norms of 20 and $100 \mathrm{ppm}$. The ranking was obtained for three chemical industries shown in Table 6.

\subsection{Comments}

As seen from the results (Table 6), the impact potential of an industry increases when the emission standards for the $\mathrm{SO}_{2}$ are made more stringent from 100 to 20 ppm. Moreover, the same is also reflected on an overall score of the industry. However, the ranking of an industry does not change. 


\section{Discussions}

From the results of different types of industries (Table 5), it can be inferred that the chemical industry ranks first in the list of nine industries with high pollution potential and the thermal power station unit ranks number nine in the list of these industries with minimum pollution potential. So in this way, it is possible to rank different types of industries on the basis of their pollution potential and it is possible to encourage industrial entrepreneurs to bring their industrial pollution potential to a minimum level by controlling pollution as an attempt to protect the environment.

\section{Conclusion}

The paper demonstrates the use of fuzzy modelling for the ranking of industries based on their air pollution potential with a case study. The sensitivity analysis reveals the pollution potential of the industry increases with stringent emission standards, however; it retains its raking. As the pollution levels in general are increasing, it is opined that the issue of pollution tax should be studied and considered by decision makers of developing countries to control the pollution levels in the environment.

\section{References}

[1] Hipel, K. W., Radford, K.J. \& Fang, L., Multiple participant multiple criteria decision-making. IEEE Trans. Syst. Man Cybern, 23,

pp. 1184-1189, 1993.

[2] Lad, R. K., Desai, N. G., Christian, R. A. \& Deshpande, A. W., Fuzzy modelling for environmental pollution potential ranking of industries. International Journal for Environmental Progress, AIChE, 27(1), pp. 84-90, 2008.

[3] Zadeh, L.A., Fuzzy Sets. Information and Control. 8(3), pp. 338-353, 1965.

[4] Klir, G.J \&Yuan, B., Fuzzy Sets and Fuzzy Logic-Theory and applications, Prentice Hall of India Private Limited: New Delhi, pp.3, 2003.

[5] Bellman, R. E. \& Zadeh, L. A., Decision-making in a fuzzy environment. Management Science, 17 (4), pp. B141-B164, 1970.

[6] Jain, R., Decision making in the presence of fuzzy variables. IEEE Trans. Systems Man Cybern, 6, pp. 698-702, 1976.

[7] Jain, R., A procedure for multiple aspect decision making using fuzzy sets. Int. J. Systems Sci., 8, 1-7, 1977.

[8] Baldwin, J. F. \& Guild, N. C. F, Comparison of fuzzy sets on the same decision space. Fuzzy Sets and Systems, 2, pp. 213-231, 1979.

[9] Adamo, J. M., Fuzzy decision tree. Fuzzy Sets and Systems, 4, 207-219, 1980.

[10] Bortolan, G. \& Degani, R., A review of some methods for ranking fuzzy subsets. Fuzzy Sets and Systems. 15, pp. 1-19, 1985. 
[11] Hagemeister, M.E., Jones, D.D. \& Woldt, W.E., Hazard ranking of landfills using fuzzy composite programming. Journal of Environmental Engineering, ASCE, 122(4), pp. 248-258, 1996.

[12] Raj, A. P., \& Kumar, N.D., Ranking alternatives with fuzzy weights using maximizing set and minimizing set. Fuzzy Sets and Systems, 105, pp. 365-375, 1999.

[13] Shen, L. Y., Li, Q. M., Drew, D. \& Shen, Q. P., Awarding construction contracts on multicriteria basis in China. Journal of Construction Engineering and Management, ASCE, 130 (3), pp. 385-393, 2004.

[14] Seo, S., Aramaki, T., Hwang, Y. \& Hanaki, K., Fuzzy decision making tool for environmental sustainable buildings. Journal of Construction Engineering and Management, ASCE, 130 (3), pp. 415-423, 2004.

[15] Singh, D. \& Tiong, R.L.K., A Fuzzy decision framework for contractor selection. Journal of Construction Engineering and Management, ASCE, 131(1), pp. 62-70, 2005.

[16] Saaty, T.L., A scaling method for priorities in hierarchical structures. $J$. Math. Psychol., 15(1), pp. 234-281, 1977.

[17] Zimmerman, H.J, Fuzzy Set Theory and its application, Kluwer Nijhoff: Hingham Mass, 1985.

[18] Klir, G. J. \& Folger, T. A., Fuzzy sets, uncertainty and information, Prentice-Hall: Englewood Cliffs, N. J., 1988.

[19] Kaufmann, \& Gupta, M. M., Fuzzy mathematical models in engineering and management science, North-Holland, Amsterdam, The Netherlands, 1988.

[20] Hwang, C. L. \& Yoon, K., Multiple attribute decision making-methods and applications, Springer: New York. 